\title{
Choque séptico puerperal por Streptococcus $\beta$-hemolítico e síndrome de Waterhouse-Friderichsen
}

\author{
Puerperal septic shock due to $\beta$-hemolytic Streptococcus \\ and Waterhouse-Friderichsen syndrome
}

\author{
Stanley de Almeida Araújo ${ }^{1}$, Ana Maria Arruda Lana ${ }^{1}$, \\ Paula Piedade Garcia ${ }^{1}$ e Pérsio Godoy ${ }^{1}$
}

\begin{abstract}
RESUMO
É relatado caso excepcional de puérpera de 15 anos com choque séptico pelo Streptococcus beta-hemolítico do grupo A e síndrome de WaterhouseFriderichsen, observado à necropsia. São revistos aspectos do diagnóstico, patogênese e evolução da infecção (sepse) puerperal associada à hemorragia e insuficiência das supra-renais.
\end{abstract}

Palavras-chaves: Síndrome de Waterhouse-Friderichsen. Hemorragia adrenal bilateral. Estreptococos $\beta$-hemolítico do grupo A. Infecção puerperal.

\section{ABSTRACT}

An exceptional case of a 15-year-old puerpera with septic shock caused by Group A $\beta$-hemolytic Streptococcus and Waterhouse-Friderichsen syndrome is reported. The findings were observed at the necropsy. The characteristics of the diagnosis, pathogenesis and evolution of this puerperal infection (sepsis), associated with adrenal hemorrhage and insufficiency are reviewed in this paper.

Key-words: Waterhouse-Friderichsen syndrome. Bilateral adrenal hemorrhage. Group A $\beta$-hemolytic Streptococcus. Puerperal infection. .

A infecção puerperal, geralmente causada por bactérias da microbiota vaginal, representa causa comum de morte materna ${ }^{12}$. Entre os fatores de risco, estão más condições de assepsia, parto prolongado, presença de restos ovulares, baixa resposta imunitária e cirurgia cesariana.

Cerca de $10 \%$ a $30 \%$ das mulheres apresentam colonização por estreptococos no trato genital inferior ou reto. Na maioria das gestantes, ocorre infecção assintomática e apenas $2 \%$ a $4 \%$ evoluem para infecção do trato urinário inferior. 0 estreptococo do Grupo B pode determinar infecção neonatal, constituindo a principal causa de morbi-mortalidade perinatal. Atualmente, realiza-se a partir da trigésima sexta semana de gestação, cultura genital e perianal para estreptococos. 0 objetivo é prevenir pela profilaxia com antibióticos, a infecção neonatal. O Streptococcus $\beta$-hemolíticos do grupo A (SßHGA) é capaz de causar afecções clínicas, incluindo a própria infecção puerperal, faringite, febre reumática, piodermite, fasciite necrotizante e síndrome do choque tóxico ${ }^{13}$

\footnotetext{
1. Departamento de Anatomia Patológica e Medicina Legal, Faculdade de Medicina, Universidade Federal de Minas Gerais, Belo Horizonte, MG.

Endereço para correspondência: Dr. Stanley de Almeida Araújo. Rua Carangola 82/604, 30330-240. Belo Horizonte, MG.

Tel: 553197937655

e-mail: stanleyaa@gmail.com

Recebido para publicação em 02/10/2008

Aceito em 30/01/2008
}

A instalação de quadro séptico no puerpério constitui grave risco à vida materna, especialmente na África, Ásia e América Latina. No tratamento, permanece em discussão o uso de corticosteróides ${ }^{1}$. A corticoterapia seria necessária nos pacientes com insuficiência adrenal aguda, em decorrência da instalação da síndrome de Waterhouse-Friderichsen (SWF) ${ }^{2}$.

A associação da infecção por S $\beta$ HGA com a SWF é excepcional sendo encontrados apenas cinco casos, em procura realizada na base de dados do MEDLINE, LILACS, SciELO e COCHRANE. Esse seria 0 sexto caso relatado e o primeiro envolvendo puerperas ${ }^{345}$.

\section{RELATO DE CASO}

Paciente de 15 anos de idade, primípara, parto vaginal na trigésima nona semana de gestação, sem intercorrências obstétricas, tais como ruptura prematura das membranas amnióticas, trabalho de parto prolongado, febre materna intraparto ou complicações fetais. No segundo dia de puerpério, apresentou dor abdominal e sangramento vaginal, associados à febre, algúria, polaciúria, diarréia, prostração, dispnéia, palpitações e mialgia generalizada. Admitida no Hospital das Clínicas da Universidade Federal de Minas Gerais (UFMG), consciente, bem orientada e ansiosa; exibia mucosa oral hipocorada, desidratação, cianose e exantema morbiliforme no tórax e abdômen. Pressão arterial: 110/80 mmHg, frequiência cardíaca 136 bpmin, freqüência respiratória 36 irpmin e temperatura axilar $37,2^{\circ} \mathrm{C}$. Extremidades 
quentes, perfusão capilar diminuída e pulso filiforme. Abdômen normotenso, doloroso à palpação profunda no flanco direito; peristaltismo preservado. Punho-percussão lombar à direita positiva. 0 exame ginecológico mostrou útero contraído, palpável a dois centímetros abaixo da cicatriz umbilical, colo aberto, central, eliminando lóquios sanguinolentos. Os exames complementares mostravam: gasometria arterial $\mathrm{pH} 7.18$, bicarbonato $10 \mathrm{mmol} / \mathrm{L}$, Base excess $10.0 \mathrm{mEq} / \mathrm{L}, \mathrm{PCO} 17 \mathrm{mmHg}$, $\mathrm{PO}_{2} 76,3 \mathrm{mmHg}$ e saturimetria $92,4 \%$; hemoglobina $10,0 \mathrm{~g} / \mathrm{dL}$, hematócrito $31,7 \%$, plaquetas $30.000 \mathrm{~mm}^{3}$, global de leucócitos $2.800 \mathrm{~mm}^{3}$ (neutrófilos segmentados $1.142 \mathrm{~mm}^{3}$ e neutrófilos bastonetes $700 \mathrm{~mm}^{3}$ ), linfócitos $672 \mathrm{~mm}^{3}$, eosinófilos $28 \mathrm{~mm}^{3} \mathrm{e}$ monócitos de $28 \mathrm{~mm}^{3}$; RNI de 3.0 e tempo de tromboplastina parcial ativado de 104" ( 29"controle). Hemoculturas 3 amostras positivas para $S \beta H G A$.

Recebeu o diagnóstico de septicemia secundária a provável foco infeccioso genitourinário, acompanhada de acidose metabólica e distúrbios de coagulação, sendo prescrito, então, oxigenioterapia, reposição volêmica vigorosa, transfusão de concentrado de hemácias, administração de norepinefrina, dobutamina, bicarbonato de sódio e antibioticoterapia (gentamicina, clindamicina e ampicilina). Evoluiu, apesar dessas medidas, em confusão mental, piora do padrão respiratório, choque refratário, colapso circulatório (extremidades frias e pálidas, pressão arterial indetectável, ausência de pulsos periféricos, perfusão capilar muito lenta), anúria, extensão do exantema, progredindo rapidamente para falência orgânica múltipla. A paciente foi reanimada depois de parada cardiorespiratória, porém faleceu após segundo episódio, seis horas após admissão.

Necropsia. Endomiometrite, cervicite e colpites agudas bacterianas necro-hemorrágicas; decídua e endométrio basal substituídos por necrose e hemorragia, constituindo coágulos, e associadas a numerosas colônias bacterianas (cocos Gram positivos); trombose em vasos de diversos calibres, muitos encerrando colônias bacterianas (Figura 1). Hidroperitônio sero-hemorrágico $(400 \mathrm{ml})$.

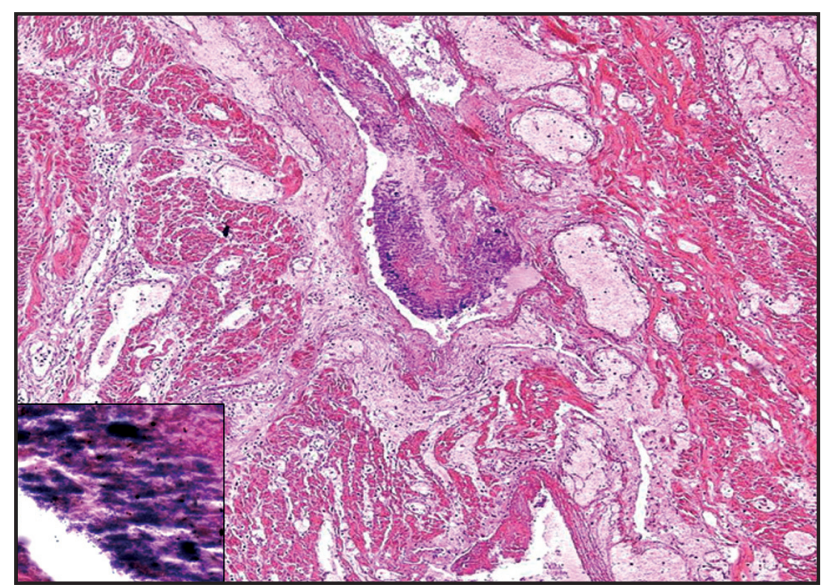

\section{FIGURA 1}

Endometrite aguda bacteriana necro-hemorrágica, associadas a numerosas colônias bacterianas (cocos Gram positivos, em detalhe). Trombose em vasos de diversos calibres, muitos encerrando colônias bacterianas.
Coagulação intravascular disseminada, observada especialmente nos rins. Necrose tubular aguda. Diátese hemorrágica: hemorragia e necrose das supra-renais (Figura 2 A, B), constituindo a SWF, acometendo grande parte das glândulas; hemorragia na mucosa do trato respiratório e digestivo; focos de hemorragia subepicárdicos,
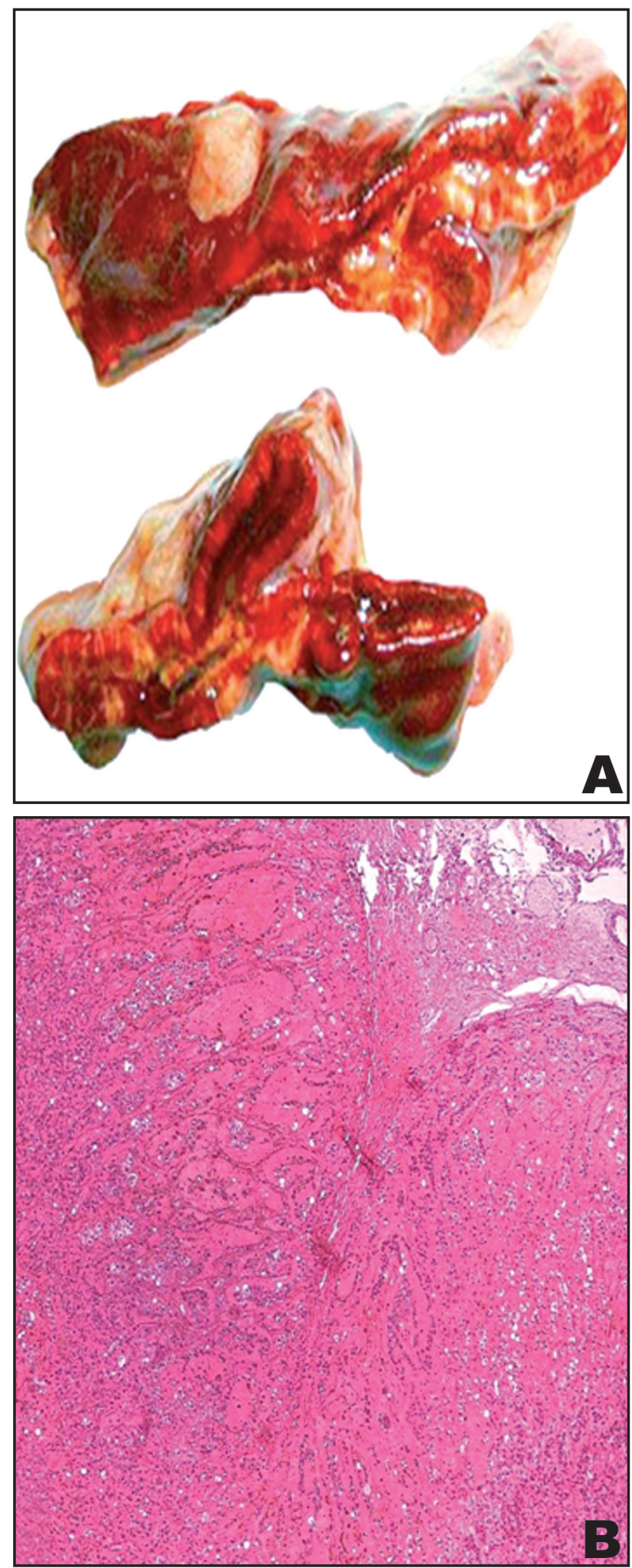

FIGURA 2

Hemorragia e necrose das supra-renais, acometendo grande parte das glândulas (aspecto macroscópico e microscópico). 
na mucosa vesical, ovários e baço. Hemorragia na região cervical inferior, bilateral, envolvendo a musculatura esquelética e esôfago, estendendo ao mediastino superior-anterior. Medula óssea com focos de necrose isquêmica e discretamente hipercelular à custa da série mielóide, demonstrando distúrbio da maturação.

Broncopneumonia purulenta em pequenos focos. Trombose de pequenos vasos, necrose e hemorragia de diminutas áreas, em correspondência; são comuns as colônias bacterianas. Dano alveolar difuso. Peso do pulmão direito: 640g; do esquerdo: 635 g. Hidrotórax bilateral $(800 \mathrm{ml}$ à direita e $700 \mathrm{ml}$ à esquerda de líquido amarelo-citrino).

Edema cerebral moderado/intenso. Hérnia de uncus e das tonsilas cerebelares (peso do encéfalo: $1.390 \mathrm{~g}$ ). Material colhido na leptomeninge durante a necropsia foi positivo para S HGA.

\section{DISCUSSÃO}

A infecção estreptocócica invasiva exterioriza-se através de sepse puerperal, escarlatina maligna, erisipela, fascciite necrosante, gangrena e miosite ${ }^{13}$. 0 alcoolismo, idade (>65 anos), diabetes, câncer, doença pulmonar obstrutiva crônica, cardiopatias, uso de corticosteróides e outros imunossupressores, drogas injetáveis, síndrome da imunodeficiência humana adquirida e varicela favorecem a infecção ${ }^{9}$. A porta de entrada do Streptococcus do Grupo A (SGA) inclui a pele ou mucosas, embora indefinida em cerca de 45\% dos casos; as mucosas servem mais como fonte da bactéria do que sítio de infecção. Parto vaginal, histerectomia, lipoaspiração e colocação de próteses são exemplos de porta de entrada. Raramente, o microorganismo é adquirido pela transmissão interpessoal ${ }^{13}$.

Atualmente, apesar das medidas preventivas, a infecção puerperal continua freqüente nos paises em desenvolvimento, relacionada, portanto, com fatores sócio-econômicos. Nos paises desenvolvidos, após aparente declínio, houve crescimento no número de casos na década de 80 e ainda, persiste como complicação obstétrica importante ${ }^{8}$.

Os principais fatores de risco para infecção puerperal são: más condições de antissepsia, ruptura prematura das membranas ovulares, trabalho de parto prolongado, múltiplos exames vaginais, monitorização interna, anemia, doenças crônicas debilitantes. Entretanto, o grande fator de risco é a operação cesariana, três a 30 vezes maior, quando comparada ao parto vaginal ${ }^{8}$.

A infecção surge da colonização bacteriana no local de implantação da placenta, que representa a região mais vulnerável, atingindo a decídua e, devido à presença de vasos abertos, especialmente as veias miometriais, alcança o miométrio, causando a endomiometrite, como no caso descrito. Havia endoparametrite (metrite com celulite pélvica). Microscopicamente, observou-se área extensa de necrose, hemorragia, constituindo coágulos, e camada subjacente de acentuada infiltração leucocitária; incontáveis colônias bacterianas em toda espessura da parede uterina e em numerosos vasos com trombos.
A necrose supra-renal está associada com alterações da coagulação, atribuídas às mudanças intravasculares do córtex, mas não diretamente com a hemorragia. Assim, a extensão da hemorragia não reflete necessariamente o grau de dano, sendo difícil, como no caso em apreço, o cálculo exato de parênquima glandular remanescente. 0 exame anatomopatológico demonstrou, ainda, coagulação intravascular disseminada e lesões correspondentes a choque. A broncopneumonia, incluindo a presença de colônias bacterianas, poderá estar diretamente relacionada ao $\mathrm{SGA}$.

Streptococcus do grupo A (SGA) são cocos Gram positivos que apresentam mais de 100M-sorotipos ${ }^{9}$. A velocidade pela qual a SGA induz infecção local, falência orgânica múltipla e morte não se compara a nenhum outro organismo infeccioso ${ }^{13}$. Os sorotipos M1, M3 e M 18 estão mais associados com a doença fatal ou invasiva ${ }^{4}$.

A capacidade de invasão aliada à necrose extensa de tecidos ocasiona grande inóculo de bactérias, larga produção de exotoxinas e insuficiência de resposta ao tratamento apenas com antibióticos. A despeito de ser bactericida para o estreptococo, a penicilina não possui efeito sobre as exotoxinas, além de ser ineficaz contra o grande inóculo bacteriano, pelo baixo ritmo de replicação do $\mathrm{S} \beta \mathrm{HGA}^{16}$. Como as penicilinas atuam inibindo a síntese na parede celular, associam-se macrolídeos, que bloqueiam a produção protéica bacteriana e, consequentemente a síntese de toxinas. 0 quadro infeccioso determina acometimento sistêmico, sendo muitas vezes necessária à realização de intervenção cirúrgica, incluindo a histerectomia, para se evitar acidose e falência orgânica múltipla ${ }^{9}{ }^{16}$. Alguns recomendam 0 uso de imunoglobulinas IV adjuvante em infecções graves, que atuariam ligando-se às toxinas circulantes.

A síndrome Waterhouse-Friderichsen, também conhecida como púrpura fulminans, é definida como necrose hemorrágica maciça e aguda das glândulas supra-renais (apoplexia adrenal), no decurso de sepse grave ${ }^{214}$. Causada por infecção meningocócica em $80 \%$ dos casos, restando 20\% para infecções decorrentes de Pneumococos, Staphylococcus sp, S $\beta \mathrm{HGA}$, Pasteurella multocida, Plesiomonas shigelloides, Haemophilus influenza, Bacilus diphteriae, Neisseria gonorrbae, Mycoplasma pneumoniae $^{2}{ }^{14}$. É mais freqüente na faixa pediátrica e entre adultos jovens.

Como no caso descrito, é condição infreqüentemente diagnosticada em vida, geralmente, através de tomografia computadorizada realizada por outras razões ${ }^{10}$. Originalmente, portanto, o diagnóstico é anatomopatológico. 0 quadro clínico é súbito, a princípio inespecífico, semelhante à doença viral benigna, devendo, todavia, chamar atenção a presença de febre, associada à cianose intermitente, dispnéia, púrpura (mais de 75\% dos pacientes desenvolvem rash generalizado) e hipotensão, que resulta progressivamente em profundo colapso circulatório e choque $^{214}$.

Manifesta-se, ainda, com dor abdominal difusa ou localizada nos flancos, relatada em $77 \%$ dos pacientes ${ }^{15}$. Náuseas e vômitos ocorrem em 46\%; soma-se leucocitose com eosinofilia. Não raramente, convulsões, modificações do estado mental, tremores e 
distúrbios da coagulação, compatíveis com coagulação intravascular (CID). Azotemia surge em 2/3 dos casos, pré-renal a princípio, depois parenquimatosa, como decorrência de necrose tubular aguda ou cortical. Hiponatremia, hipoalbuminemia e hiperglicemia são também citadas. Hipoglicemia surge raramente em hemorragias adrenais bilaterais sintomáticas e se presente pode ser secundária a sepse por Gram negativos ${ }^{15}$. A bioquímica pode mostrar um elevado hiato aniônico por acidose metabólica ${ }^{14}$.

No caso em estudo havia CID sendo, porém, difícil estabecelecer sua relação cronológica com hemorragia das supra-renais. Quando a doença progride e aparece extenso rash purpúrico, a mortalidade alcança mais de $50 \%$ dos casos ${ }^{14}$.

Nenhuma outra infecção determina óbito tão rápido, com poucas horas, mesmo com assistência hospitalar intensiva ${ }^{2}$. Muitos autores compartilham da opinião que o mau prognóstico da doença seja devido à insuficiência supra-renal aguda, decorrente da apoplexia adrenal, que a distingue de outras septicemias ${ }^{2}$. Indícios de insuficiência supra-renal incluem hipotensão persistente, apesar do volume circulante adequado, circulação hiperdinamica e baixa resistência vascular; o não reconhecimento da falência glandular pode ser fatal, levando ao óbito em seis a 48 horas 6 . Todavia, a hemorragia bilateral das supra-renais nem sempre se acompanha de sinais clínicos ou funcionais de insuficiência glandular.

Na patogênese da SWF haveria, inicialmente, liberação dos corticosteróides disponíveis nas glândulas, secreção de ACTH e aumento adicional de corticosteróides, depleção lipídica e ablação fisiológica das supra-renais, justo quando mais necessária é a produção hormonal; a estimulação pelo ACTH teria relação com alterações degenerativas e/ou hemorragia da glândula. A exaustão e parada da função das adrenais exerceria papel crítico nas infecções graves, facilitando a hemorragia ${ }^{15}$. 0 diagnóstico de insuficiência das supra-renais é auxiliado pela dosagem do cortisol plasmático por estímulo da glândula pelo ACTH.

A hemorragia bilateral das supra-renais não está associada exclusivamente com a SWF, mas com a estimulação adrenocortical por hormônio adrenocorticotrófico exógeno, sepse (toxinas), stress, desordens hemorrágicas e deficiências nutricionais ${ }^{10}$.

A administração precoce de corticosteróides é imperativa na insuficiência supra-renal aguda da SWF, especialmente nos pacientes criticamente enfermos ${ }^{6}$. Atuam melhorando o estado hemonodinâmico, diminuindo a resposta inflamatória (o choque séptico representa a mais intensa reposta inflamatória sistêmica) e alterando os indicadores de mortalidade ${ }^{11}$.

\section{REFERÊNCIAS}

1. Balk RA. Steroids for septic shock: back from the dead? Chest 123: 490S-499S, 2003 .

2. Friderichsen C. Waterhouse-Friderichsen syndrome (WFS) Acta Endocrinologica 18: 482-492, 1955.

3. Gertner M, Rodriguez L, Barnett SH, Shah K. Group A beta-hemolytic Streptococcus and Waterhouse-Friderichsen syndrome. The Pediatric Infectious Disease Journal 11: 595-596, 1992.

4. Givner LB. Invasive disease due to group A beta-hemolytic streptococci: continued occurrence in children in North Carolina. Southern Medical Journal 91: 333-337, 1998.

5. Hamilton D, Harris MD, Foweraker J, Gresham GA. Waterhouse-Friderichsen syndrome as a result of non-meningococcal infection. Journal of Clinical Pathology 57: 208-209, 2004.

6. Jacobi J. Corticosteroid replacement in critically ill patients. Critical Care Clinics 22: 245-253, 2006.

7. Karakousis PC, Page KR, Varello MA, Howlett PJ, Stieritz DD. WaterhouseFriderichsen syndrome after infection with group A streptococcus. Mayo Clinic Proceedings 76: 1167-1170, 2001.

8. Lydon-Rochelle M, Holt VL, Martin DP, Easterling TR. Association between method of delivery and maternal rehospitalization. Journal of American Medical Association 283: 2411-2416, 2000.

9. Martin JM, Green M. Group A Streptococcus. Seminars in Pediatric Infectious Diseases 17: 140-148, 2006.

10. Picolos MK, Nooka A, Davis AB, Raval B, Orlander PR. Bilateral adrenal hemorrhage: an overlooked cause of hypotension. Journal of Emergency Medicine 32: 167-169, 2007.

11. Raghavan M, Marik PE. Management of sepsis during the early "golden hours". Journal of Emergency Medicine 31: 185-199, 2006.

12. Ronsmans C, Graham WJ. Lancet Maternal Survival Series Steering Group. Maternal mortality: who, when, where, and why. Lancet 368: 1189-2000, 2006.

13. Stevens DL. Invasive group A streptococcus infections. Clinical Infectious Diseases 14: 2-11, 1992.

14. Varon J, Chen K, Sternbach GL. Rupert Waterhouse and Carl Friderichsen: adrenal apoplexy. Journal of Emergency Medicine 16: 643-647, 1998.

15. Xarli VP, Steele AA, Davis PJ, Buescher ES, Rios CN, Garcia-Bunuel R. Adrenal hemorrhage in the adult. Medicine (Baltimore) 57:211-221, 1978.

16. Wood TF, Potter MA, Jonasson 0. Streptococcal toxic shock-like syndrome. The importance of surgical intervention. Annals of Surgery 217: 109-114, 1993. 